In: ISMÉRIO, Clarisse (Org.). Patrimônio Cultural: simbolismos, intertextualidades e polifonias [livro eletrônico]. São Paulo: Vecher, 2021. Disponível em: <https://doi.org/10.47585/9786599324215>.

\title{
O Artesanato e o Patrimônio Cultural: a produção acadêmica dos programas de pós-graduação em Patrimônio Cultural
}

Cátia Silveira e Rafael Milheira ${ }^{2}$

doi.org/10.47585/9786599324215.1

Nesse trabalho, apresentamos um estado da arte/do conhecimento, sobre o que vem sendo produzido a respeito da temática Patrimônio Cultural no âmbito acadêmico, no Brasil. Trata-se de um levantamento sobre a produção dos Programas de Pós-Graduação stricto sensu em Patrimônio Cultural, a partir dos campos informativos da Plataforma Sucupira, bem como, da produção acadêmica desses, no que se refere ao artesanato na abordagem do patrimônio cultural, no período de 2003 a 2017. Com base nesses dados foi possível medir o baixo impacto da produção dos programas no que se refere ao tema artesanato, o que reflete a forma como esse campo de produção cultural é tratado no Brasil.

Palavras-chave: Patrimônio Cultural; Artesanato; Estado da Arte.

\footnotetext{
1 Mestre em Patrimônio Cultural pela Universidade Federal de Santa Maria. Mestranda em Ensino de História da Universidade Federal de Santa Maria, http://lattes.cnpq.br/6606143066786980, e-mail: catilusilveira@gmail.com.

2 Departamento de Antropologia e Arqueologia. Coordenador do Programa de Pós-graduação em Antropologia da Universidade Federal de Pelotas. Colaborador no Programa de Pós-graduação em Patrimônio Cultural da Universidade Federal de Santa Maria. Coordenador do Laboratório de Ensino e Pesquisa em Antropologia e Arqueologia (LEPAARQ/UFPel), http://lattes.cnpq.br/2765334557326646, e-mail: milheirarafael@gmail.com.
} 


\section{Introdução}

Diante dos fomentos às ações/pesquisas e reconhecimentos por órgãos nacionais e internacionais no que se refere ao Patrimônio Cultural Brasileiro e do crescente número de Programas de Pós-Graduação em Patrimônio, surge o questionamento de por que, apesar desses fomentos, ainda tem-se uma escassa literatura no que concerne à questão da valorização e reconhecimento da produção artesanal como Patrimônio Cultural?

O Patrimônio Cultural do Brasil vai além de edificações tombadas e bens materiais. As tradições da vida popular, os modos de fazer coletivos, as celebrações, os ritmos e as danças são considerados bens imateriais do país, previstos pela Constituição Federal de 1988 e também pela Organização das Nações Unidas para a Educação, a Ciência e a Cultura (Unesco).

Uma política de proteção dos bens imateriais começou a ser implementada pelo Instituto do Patrimônio Histórico e Artístico Nacional (Iphan), a partir da criação do Departamento do Patrimônio Imaterial (DPI). Cabe registrar que o Decreto $n^{\circ} 3.551$, de 4 de agosto de 2000, é considerado um marco na inclusão do tema do patrimônio imaterial, instituindo o Registro de Bens Culturais de Natureza Imaterial e criando, também, o Programa Nacional do Patrimônio Imaterial - PNPI, executado pelo Iphan. Atualmente, são quarenta e oito bens imateriais registrados em todo o Brasil, classificando o artesanato ou o modo de fazer artesanal como parte integrante do patrimônio imaterial ${ }^{3}$.

Tal caracterização sobre o artesanato se dá por meio de um conhecimento inseparável dos agentes concretos que ao longo de sua história o praticam. Ele não é apenas um saber, mas um "saber fazer", um conhecimento palpável que se preserva na medida em que é realizado, de construção e reconstrução permanente (MOURA, 2015).

De acordo com dados da Coordenação de Aperfeiçoamento de Pessoal de Nível Superior (Capes), fundação ligada ao Ministério da Educação, o primeiro Programa de Pós-Graduação em Patrimônio Cultural, no Brasil, iniciou suas atividades nos anos 2000, na Pontifícia Universidade Católica do Estado de Goiás. No entanto, o referido PPG em Gestão do Patrimônio Cultural encontra-se desativado desde 2010. Observa-se, frente às buscas na Plataforma de Gerenciamento dos Programas de Pós-Graduação, que a partir do ano de 2006 tem-se uma frequência anual no início de funcionamento dos programas com a denominação Patrimônio e/ou Patrimônio Cultural.

No âmbito das políticas culturais, relacionadas ao período mencionado acima, a hipótese que se levanta sobre as ações nesse campo, implementadas no Brasil nos últimos anos, infere sobre as leituras dos processos por meio dos quais são estabelecidas articulações entre Estado e a mobilização da sociedade, com consequente reflexo no meio acadêmico.

\footnotetext{
3 Disponível em: <http://portal.iphan.gov.br/pagina/detalhes/606>. Acesso em: 10 out. 2019. Os patrimônios registrados são os bens culturais imateriais reconhecidos formalmente como Patrimônio Cultural do Brasil. Esses bens caracterizam-se pelas práticas e domínios da vida social apropriados por indivíduos e grupos sociais como importantes elementos de sua identidade. São transmitidos de geração a geração e constantemente recriado pelas comunidades e grupos em função de seu ambiente, sua interação com a natureza e sua história, gerando um sentimento de identidade e continuidade. Contribuem, dessa forma, para promoção do respeito à diversidade cultural e à criatividade humana.
} 
Aponta-se a ocorrência de uma importante inflexão no rumo das políticas públicas culturais, no campo das ações governamentais, desde o início dos anos 2000, cabendo citar o Programa Cultura Viva, sobretudo, por meio das implantações dos Pontos de Cultura, que ampliaram o processo de mobilização dos produtores culturais, envolvendo mais de quatro mil municípios em todo o país, em consonância com ações para a preservação da diversidade cultural, destacadas como um dos principais eixos das ações do Ministério da Cultura (VIEIRA, 2016).

Nesse contexto, apresentaremos algumas métricas sobre as produções acadêmicas relativas à produção artesanal no âmbito do Patrimônio Cultural, compondo um estado da arte ou estado do conhecimento, a partir das dissertações e teses dos programas de pós-graduação stricto sensu em Patrimônio Cultural no âmbito nacional. O que e o quanto se produziu academicamente sobre o tema artesanato, enquanto concepção do patrimônio cultural, num recorte temporal do ano de 2003 a 2017, em consonância com as ações de promoção e valorização da cultura no Brasil.

Após o mapeamento dos Programas de Pós-Graduação, na Plataforma Sucupira, ferramenta utilizada para coletar informações, realizar análises e avaliações, que é a base de referência do Sistema Nacional de Pós-Graduação - SNPG, foram elencados dezesseis Programas de Pós-Graduação, totalizando dezenove cursos entre Mestrado, Mestrado Profissional e Doutorado. Destes dezesseis programas, apenas oito são denominados Programa de Pós-Graduação em Patrimônio Cultural, objeto da pesquisa.

A busca nos repositórios das Universidades e dos Programas de Pós-graduação elencados pela Plataforma Sucupira apontou um resultado mais satisfatório do que nos dados constantes na plataforma, gerando dezesseis dissertações e nenhuma tese. Para tal, obedeceu-se aos critérios de busca por palavra-chave, título e/ou assunto e posterior análise dos resumos e dos trabalhos na íntegra. Destas, dez dissertações são oriundas dos PPGs em Patrimônio Cultural e foram o objeto de análise e discussão que se seguirá.

Cabe aqui destacar a predominância de produção vinculada a PPGs da área de História. Apesar do reconhecimento do artesanato como patrimônio cultural imaterial, os PPGs em Patrimônio cultural não apresentam linhas de pesquisas voltadas à referida temática. A descrição das atividades artesanais, apontadas pelas dissertações, destacam a condição de subsistência social e econômica do artesão, principalmente ligada às mulheres, bem como, aspectos de convergência e motivação para as pesquisas, como condição da subsistência de identidades e tradições culturais e a sua desvalorização frente à competição mercadológica.

\section{Percurso metodológico}

A primeira etapa metodológica desta pesquisa se deu a partir da seleção de uma bibliografia que contemplasse a definição e construção conceitual do objeto da pesquisa. Dentre estes, optou-se pela realização de uma pesquisa denominada estado da arte ou estado do conhecimento, visto que o objetivo era quantificar e qualificar as produções acadêmicas sobre o assunto proposto.

Desse modo, a pesquisa que tem caráter investigativo, descritivo e analítico orientou-se nos 
estudos de Norma Ferreira (2002), a fim de respaldar os procedimentos. Sobre as definições das pesquisas denominadas o "Estado da Arte" e o "Estado do Conhecimento", a autora infere:

Definidas como de caráter bibliográfico, elas parecem trazer em comum o desafio de mapear
e discutir uma certa produção acadêmica em diferentes campos do conhecimento, tentando
responder que aspectos e dimensões vêm sendo destacados e privilegiados em diferentes
épocas e lugares, de que forma e em que condições têm sido produzidas certas dissertações
de mestrado e teses de doutorado, publicações em periódicos e comunicações em anais de
congressos e seminários. Também são reconhecidas por realizarem uma metodologia de
caráter inventariante e descritivo da produção acadêmica e científica sobre o tema que busca
investigar, à luz de categorias e facetas que se caracterizam enquanto tais em cada trabalho e
no conjunto deles, sobre os quais o fenômeno passa a ser analisado. (FERREIRA, 2002, p. 265)

Nesses termos, a principal motivação para esse tipo de pesquisa se pauta na profusão dos estudos e pesquisas, principalmente, oriundas pelos inúmeros Programas de Pós-graduação e a sensação de pouco conhecimento da sua totalidade e de sua divulgação.

Magda Soares (apud FERREIRA, 2002) ressalta que essa compreensão do estado de conhecimento sobre um tema, em determinado momento, "é necessária no processo de evolução da ciência", com o propósito de ordenar "periodicamente o conjunto de informações e resultados já obtidos", permitindo a partir desse ordenamento, "indicação das possibilidades de integração de diferentes perspectivas, aparentemente autônomas, a identificação de duplicações ou contradições, e a determinação de lacunas e vieses.” (p. 259).

Segundo Ferreira (2002), existem dois momentos a serem avaliados a partir da escolha metodológica da pesquisa do estado da arte. Sendo estes: quantificar e identificar os dados bibliográficos mapeando a produção em um período delimitado e área de produção; e um segundo momento, que é o objetivo desta pesquisa, em relação às possibilidades de inventariar a produção analisando tendências, ênfases, escolhas metodológicas e teóricas, aproximando ou distanciando do trabalho entre si, na escrita de uma determinada área do conhecimento.

Neste trabalho optou-se pelo acesso às pesquisas através dos Programas de Pós-graduação e dos resumos, em seguida a busca das dissertações e teses na íntegra, buscando reconhecer como e o que está sendo discutido.

No intuito de atender às demandas estabelecidas para a pesquisa, sobre a relação e/ou a valorização do artesanato e do patrimônio cultural a partir das produções acadêmicas dos programas de pós-graduação stricto sensu em Patrimônio e em Patrimônio Cultural no Brasil, buscou-se dentro dos Periódicos da Capes, na Base de Dados de Teses e Dissertações (BDTD) e nos repositórios das Universidades que não estavam indexadas na BDTD. No entanto, essa busca não atendeu aos objetivos da pesquisa, pois verificou-se que há um descompasso entre a produção dos PPGs e a atualização das Bases de Dados.

Definidas as especificações e justificativas para a delinear a metodologia, e a partir dos insucessos diante das buscas nas plataformas anteriormente mencionadas, a pesquisa voltou-se para a Plataforma Sucupira, mapeando os Programas de Pós-graduação no Brasil que apresentavam na sua 
denominação as categorias Patrimônio e Patrimônio Cultural.

Conforme a Capes (2014), a Plataforma Sucupira é uma ferramenta para coletar informações, realizar análises e avaliações e constitui-se na base de referência do Sistema Nacional de PósGraduação - SNPG, disponibilizando, entre outros dados, o Coleta Capes, com os dados cadastrais dos Programas de Pós-Graduação, dados e estatísticas, além dos dados quantitativos dos cursos avaliados e reconhecidos pela Capes.

A fim de sistematizar os dados coletados para a pesquisa na Plataforma Sucupira, organizou-se uma tabela, com base inicialmente no Coleta Capes e posterior cruzamento de dados da aba Dados e Estatísticas, composta pelos Programas de Pós-graduação, instituições, área, situação, modalidade e avaliações dos cursos.

A partir das informações, buscou-se as especificações de cada um dos programas, a fim de identificar quais eram os cursos, ano de início e situação de funcionamento. Desse modo, organizouse uma nova tabela de arquivo, abordando essas informações.

Há que se observar que existem problemas na Plataforma Sucupira, em relação à definição dos programas pela palavra patrimônio. A plataforma não admite diferentes grafias para a mesma palavra, sendo estas: Patrimônio; Patrimonio, sem acento circunflexo; e Patrimönio, com o uso da marcação trema. No entanto, apresenta programas, a exemplo da Unirio, que será apresentado a seguir, no quadro dos resultados dos Programas e Cursos, grafados como Museologia e Patrimönio, excluindo-o dos resultados da busca; além de outros programas e cursos de instituições que não aparecem no acesso Coleta Capes e que se apresentam nos Dados e Estatísticas da Plataforma Sucupira.

A partir da identificação dos programas que apresentavam a denominação Patrimônio, organizou-se fichas para uma descrição dos Programas de Pós-graduação em Patrimônio Cultural, objeto desta pesquisa, a fim de descrever a constituição do programa, abordando seu histórico, sua proposta e a constituição do corpo docente, quantitativa e qualitativamente, através das suas áreas de conhecimento.

O mapeamento teve recorte temporal de 2003 a 2017. Inicialmente se fez a busca a partir de palavras-chave, posteriormente por assuntos, sempre com os descritores Artesanato e Patrimônio Cultural, primeiro separadamente e, em seguida, junto com a utilização de operadores de busca. Por fim, a busca nos resumos das dissertações nos repositórios das universidades elencadas mostrou-se mais eficientes e, supostamente, mais completa. Nesse ponto da pesquisa, considerou-se organizar as produções acadêmicas sobre a temática por ano, título, autor, orientador, programa e tipo de documento, se dissertação ou tese.

\section{Os PPGs, as produções e seus autores}

Definido o critério de identificação dos PPGs a partir das denominações Patrimônio e Patrimônio Cultural, as buscas dentre os 4.589 Programas de Pós-graduação avaliados e reconhecidos pela Capes retornaram os resultados apresentados no quadro 1, em que os 16 Programas de Pós-Graduação em Patrimônio Cultural e/ou que trazem em sua designação a 
palavra Patrimônio, critério este, previamente estabelecido para a busca. Destes, o Programa de Pós-Graduação em Gestão do Patrimônio Cultural, da Pontifícia Universidade Católica de Goiás, encontra-se desativado desde 2010. O quadro construído a partir do cruzamento de dados cadastrais dos programas do Coleta CAPES e dos Dados e Estatísticas, ambos Plataforma Sucupira, elenca os PPGs denominados Patrimônio e Patrimônio Cultural, organizados em ordem alfabética.

Observa-se, também, que alguns programas têm cursos recentemente criados ou apresentam a data de início das suas atividades posteriores ao recorte temporal desta pesquisa não resultando produções acadêmicas elencadas e analisadas. No entanto, foram mantidos para fins de mapeamento e identificação da constituição dos Programas de Pós-graduação denominados Patrimônio Cultural.

Tabela 1 - IES, Programas e Cursos de Pós-Graduação, ano de início de funcionamento

\begin{tabular}{|c|c|c|c|c|c|c|c|}
\hline IES & Programa & Curso & Ano de Início & ME & DO & MP & DP \\
\hline \multirow{2}{*}{ UFMG } & $\begin{array}{l}\text { Ambiente construídoe } \\
\text { patrimônio sustentável }\end{array}$ & $\begin{array}{l}\text { Ambiente construido e } \\
\text { patrimônio sustentável }\end{array}$ & 2007 & $x$ & & & \\
\hline & $\begin{array}{l}\text { Ambiente construido e } \\
\text { património sustentável }\end{array}$ & $\begin{array}{l}\text { Ambiente construido e } \\
\text { património sustentável }\end{array}$ & 2016 & & $x$ & & \\
\hline UFRB & $\begin{array}{c}\text { Arqueologia e } \\
\text { Património Cultural }\end{array}$ & $\begin{array}{c}\text { Arqueologia e } \\
\text { Património Cultural }\end{array}$ & 2019 & $x$ & & & \\
\hline FUFPI & $\begin{array}{l}\text { Artes, Patrimônio } \\
\text { e Museologia }\end{array}$ & $\begin{array}{l}\text { Artes, Patrimônio } \\
\text { e Museologia }\end{array}$ & 2015 & & & $\mathrm{x}$ & \\
\hline UEG & $\begin{array}{c}\text { Estudos Culturais, } \\
\text { Memória e Patrimônio }\end{array}$ & $\begin{array}{c}\text { Estudos Culturais, } \\
\text { Memória e Patrimônio }\end{array}$ & 2018 & & & $x$ & \\
\hline UFRJ & $\begin{array}{c}\text { Geociências: Patrimônio } \\
\text { Geopaleontológico }\end{array}$ & $\begin{array}{c}\text { Geociências: Patrimônio } \\
\text { Geopaleontológico }\end{array}$ & 2015 & $\mathrm{x}$ & & & \\
\hline PUC-GO & $\begin{array}{c}\text { Gestăo do } \\
\text { Patrimônio Cultural }\end{array}$ & $\begin{array}{c}\text { Gestão do } \\
\text { Patrimônio Cultural }\end{array}$ & $2000-2010$ & & & $\mathrm{x}$ & \\
\hline \multirow{2}{*}{ UFPEL } & $\begin{array}{c}\text { Memória Social e } \\
\text { Património Cultural }\end{array}$ & $\begin{array}{c}\text { Memória Social e } \\
\text { Património Cultural }\end{array}$ & 2007 & $x$ & & & \\
\hline & $\begin{array}{c}\text { Memória Social e } \\
\text { Património Cultural }\end{array}$ & $\begin{array}{c}\text { Memória Social e } \\
\text { Património Cultural }\end{array}$ & 2013 & & $\mathrm{x}$ & & \\
\hline UFRGS & Museologia e Patrimônio & Museologia e Patrimônio & 2017 & $\mathrm{x}$ & & & \\
\hline \multirow{2}{*}{ UNIRIO } & Museologia e Patrimonio & Museologia e Patrimônio & 2006 & $x$ & & & \\
\hline & Museologia e Patrimônio & Museologia e Patrimônio & 2011 & & $\mathrm{x}$ & & \\
\hline UFRRJ/NI & $\begin{array}{l}\text { Património, Cultura e } \\
\text { Sociedade }\end{array}$ & $\begin{array}{c}\text { Património, Cultura e } \\
\text { Sociedade }\end{array}$ & 2017 & $\mathrm{X}$ & & & \\
\hline UFSM & Património Cultural & Patrimônio Cultural & 2008 & & & $x$ & \\
\hline \multirow{2}{*}{ UNIVILLE } & $\begin{array}{l}\text { Património Cultural } \\
\text { e Sociedade }\end{array}$ & $\begin{array}{l}\text { Património Cultural } \\
\text { e Sociedade }\end{array}$ & 2008 & $x$ & & & \\
\hline & $\begin{array}{l}\text { Património Cultural } \\
\text { e Sociedade }\end{array}$ & $\begin{array}{l}\text { Património Cultural } \\
\text { e Sociedade }\end{array}$ & 2019 & & $x$ & & \\
\hline UFV & $\begin{array}{l}\text { Patrimônio Cultural, } \\
\text { Paisagens e Cidadania }\end{array}$ & $\begin{array}{l}\text { Patrimônio Cultural, } \\
\text { Paisagens e Cidadania }\end{array}$ & 2014 & & & $\mathrm{x}$ & \\
\hline IPHAN & $\begin{array}{c}\text { Preservação do } \\
\text { Patrimônio Cultural }\end{array}$ & $\begin{array}{c}\text { Preservação do } \\
\text { Patrimônio Cultural }\end{array}$ & 2011 & & & $x$ & \\
\hline FIOCRUZ & $\begin{array}{l}\text { Preservação e Gestão do } \\
\text { Patrimônio Cultural das } \\
\text { Ciências e da Saúde }\end{array}$ & $\begin{array}{l}\text { Preservação e Gestão do } \\
\text { Patrimônio Cultural das } \\
\text { Ciências e da Saúde }\end{array}$ & 2016 & & & $x$ & \\
\hline UFRJ & Projeto e Patrimônio & Projeto e Patrimônio & 2013 & & & $x$ & \\
\hline
\end{tabular}

Fonte dos dados: Plataforma Sucupira/Coleta Capes. Organização: A autora (2019). 
A análise por área de avaliação da Capes apresentou que 62,5\% dos PPGs denominados Patrimônio Cultural estão na área de avaliação Interdisciplinar, 25\% em Antropologia/ Arqueologia e 12,5\% em História. Essa inserção interdisciplinar, segundo as informações obtidas na Plataforma Sucupira, possibilita uma formação mais diversificada e proporciona uma compreensão do Patrimônio Cultural como uma prática social.

No que se refere à constituição do corpo docente dos programas, verificou-se uma diversificada composição no campo do conhecimento. Os oito programas aqui listados são compostos por 122 docentes, destes, cerca de 33\% pertencem à área de História, 7,4\% à Arqueologia, 6,6\% à Antropologia. Outros 6,6\% pertencem à área de Arquitetura e Urbanismo e o restante está distribuído em outras 32 áreas do conhecimento.

Quanto à produção acadêmica, há que se observar que as primeiras pesquisas em Patrimônio Cultural no Brasil, oriundas dos PPGs, são anteriores às criações dos programas denominados Patrimônio Cultural.

Conforme dados do Catálogo de Teses e Dissertações, da Plataforma Sucupira, estas começam a ser apresentadas a partir do ano de 1996, sendo as primeiras oito divulgadas nesse ano divididas entre as grandes áreas do conhecimento: Ciências Sociais Aplicadas, Ciências da Saúde, Ciências Humanas e Multidisciplinar. Do ano seguinte, 1997, em diante, confere-se evidente destaque aos Programas de Pós-graduação em Arquitetura, compreendendo 327 das 3392 produções acadêmicas apontadas no período de 1996 a 2018 pela Plataforma ${ }^{4}$.Há um crescimento considerável no período de recorte temporal da pesquisa, 2003 a 2017, saltando de 81 para 394 produções acadêmicas.

Esse quantitativo está dividido em 135 áreas do conhecimento, com ênfase nas áreas de Ciências Sociais, Humanidades, Arquitetura e Urbanismo, Interdisciplinar, História, Geografia, Antropologia e Arqueologia; e em 76 áreas de avaliação, destacando-se a área Interdisciplinar, seguida por Arquitetura e Urbanismo, Antropologia/Arqueologia, História e Geografia.

Dentre os programas que mais aparecem estão os de Arquitetura, conforme mencionado anteriormente, seguido pelos PPGs em Memória e Patrimônio Cultural; em Patrimônio Cultural; em História; e em Preservação do Patrimônio Cultural. Entre as instituições que mais se destacam na produção acadêmica dessa temática, aparecem a UFSM e a UFPEL, seguidas pela UFRJ, USP e UFPE.

Outro dado importante a ser ressaltado é sobre os resultados apontados para as pesquisas acerca do patrimônio cultural, atreladas à temática do artesanato. A plataforma retorna apenas um resultado, sendo este a dissertação intitulada Narrativas e o Lugar: sobre o Artesanato Tradicional da Renda Turca de Bicos de Sabará, do ano de 2016, do Mestrado em Ambiente Construído e Patrimônio Sustentável da UFMG.

4 Dados da Plataforma Sucupira, na aba coleta CAPES. Por se tratar de uma plataforma em constante atualização, esses dados podem apresentar variações de acordo com o dia de acesso. Acesso em: 28 nov. 2019. 
Portanto, para melhor obtenção de resultados das produções de mestrado e doutorado sobre a relação entre artesanato e a valorização enquanto patrimônio cultural, foram realizadas buscas nos repositórios das universidades e programas elencados anteriormente. No período de 2003 a 2017, foram defendidas 16 dissertações de mestrado, relativas à temática abordada, no âmbito dos cursos de mestrado acadêmico e/ou mestrado profissional, no recorte temporal da pesquisa. Destas 16 dissertações, foram analisadas aquelas oriundas dos Programas de Pósgraduação denominados Patrimônio Cultural, conforme critério pré-estabelecido, restando 10 dissertações a serem abordadas, conforme tabela a seguir:

Tabela 2 - Produções acadêmicas dos PPGs em Patrimôio Cultural

\begin{tabular}{|c|c|c|c|c|c|}
\hline Ano & Título & Autor & Orientador & Programa & $\begin{array}{c}\text { Tipo de } \\
\text { documento }\end{array}$ \\
\hline 2005 & $\begin{array}{l}\text { As técnicas tradicionais das fiandeiras e } \\
\text { tecedeiras de Hidrolândia - Goiás. }\end{array}$ & BUENO, L. S. & FOGAÇA, E. & $\begin{array}{l}\text { Gestão do } \\
\text { Patrimônio } \\
\text { Cultural }\end{array}$ & Dissertação \\
\hline 2005 & $\begin{array}{l}\text { Olhos d' Água, Olhos d'Alma: de bem } \\
\text { cultural a patrimônio goiano }\end{array}$ & SANTOS, P. A. & LARAIA, R. B. & $\begin{array}{l}\text { Gestão do } \\
\text { Patrimônio } \\
\text { Cultural }\end{array}$ & Dissertação \\
\hline 2006 & $\begin{array}{c}\text { Colcha de retalhos: os Bastidores do } \\
\text { Patrimônio }\end{array}$ & BERGEROT, V. & VICENTINI, A. & $\begin{array}{l}\text { Gestão do } \\
\text { Patrimônio } \\
\text { Cultural }\end{array}$ & Dissertação \\
\hline 2009 & $\begin{array}{c}\text { Colônia de Pescadores Z3, Pelotas - RS: } \\
\text { da crise na pesca a expansão do turismo } \\
\text { com base no patrimônio cultural }\end{array}$ & FIGUEIRA, M. C. & VIEIRA, S. G. & $\begin{array}{l}\text { Memória } \\
\text { Social e } \\
\text { Patrimônio } \\
\text { Cultural }\end{array}$ & Dissertação \\
\hline 2010 & $\begin{array}{c}\text { No Caminho do Sabor e da Cultura: uma } \\
\text { abordagem sobre a cozinha e o cotidiano } \\
\text { da Estrada Bonita (Pirabeiraba } \\
\text { Joinville/SC) }\end{array}$ & ESTEVES, V. K. & SILVA, J. G. & $\begin{array}{l}\text { Patrimônio } \\
\text { Cultural e } \\
\text { Sociedade }\end{array}$ & Dissertação \\
\hline 2011 & $\begin{array}{l}\text { Patchwork: retalhos de técnica, memória, } \\
\text { arte e artesanato }\end{array}$ & CAVALIERI, M. M. & LAMAS, N. C. & $\begin{array}{l}\text { Patrimônio } \\
\text { Cultural e } \\
\text { Sociedade }\end{array}$ & Dissertação \\
\hline 2013 & $\begin{array}{l}\text { A História de um Patrimônio Cultural: A } \\
\text { Cachaça Morretiana }\end{array}$ & MEIRA, E. D. & COELHO, I. & $\begin{array}{l}\text { Patrimônio } \\
\text { Cultural e } \\
\text { Sociedade }\end{array}$ & Dissertação \\
\hline 2014 & $\begin{array}{l}\text { Valorização dos aspectos formais } \\
\text { dos artefatos confeccionados por } \\
\text { guasqueiros do pampa gaúcho } \\
\text { aplicados à joalheria }\end{array}$ & ALVARES, F. C. & HOELZEL, C.G.M & $\begin{array}{l}\text { Patrimônio } \\
\text { Cultural }\end{array}$ & Dissertação \\
\hline 2014 & $\begin{array}{c}\text { Memórias de agulhas: manifestação } \\
\text { artesanal das bordadeiras de Jaraguá do } \\
\text { Sul, Santa Catarina }\end{array}$ & RIECHEL, D. & LAMAS, N. C. & $\begin{array}{l}\text { Patrimônio } \\
\text { Cultural e } \\
\text { Sociedade }\end{array}$ & Dissertação \\
\hline 2017 & $\begin{array}{l}\text { Os mercados campesinos de Bogotá: } \\
\text { patrimônio cultural imaterial como } \\
\text { instrumento de desenvolvimento }\end{array}$ & PARRA, D. U. & COELHO, I. & $\begin{array}{l}\text { Patrimônio } \\
\text { Cultural e } \\
\text { Sociedade }\end{array}$ & Dissertação \\
\hline
\end{tabular}

Fonte: A autora.

Observa-se que os PPGs que mais produziram dissertações são aqueles que, embora não apresentem linhas de pesquisas específicas denominadas artesanato ou voltadas, especificamente, às produções artesanais, são aqueles que estão inseridos na grande área do conhecimento Interdisciplinar e subárea Social e Humanidades. Nos seus quadros figuram docentes, em sua maioria, da área de História, seguidos por docentes das áreas de Antropologia e Arqueologia. 
A análise interpretativa do currículo dos pesquisadores e dos seus respectivos orientadores possibilitou a representação desses dados em dois gráficos que evidenciam as áreas de formação e capacitação dos orientados e orientadores, bem como os reflexos nas dissertações sobre a temática do artesanato.

Destaca-se que 30\% dos pesquisadores da temática são de formação na área de História, restando outras sete áreas com um profissional em cada. Mesmo diante da impossibilidade de verificação da área do conhecimento de um dos orientadores do PPG em Gestão do Patrimônio Cultural, da PUC-Goiás, em razão da falta de informação na Plataforma Lattes, reitera a predominância da área de História também entre a capacitação dos orientadores, apontandose, assim, como a área que tem pautado as discussões do Patrimônio Cultural.

\section{Considerações finais}

O presente trabalho permite interpretar o quanto e como estes programas contribuíram para pensar o artesanato no âmbito das pesquisas sobre patrimônio cultural. A criação dos Programas Pós-Graduação em Patrimônio Cultural, a partir do ano 2000, principalmente na modalidade profissional, está atrelada, possivelmente, às prerrogativas do Programa Nacional de Patrimônio Imaterial - PNPI, de demanda de profissionais e técnicos qualificados para identificação e processos, diante de mudanças que se apresentavam além do campo conceitual referente ao entendimento do patrimônio.

Desse modo, a implantação do programa teria demandado muito mais dos interesses dos pesquisadores do IPHAN ou da comunidade acadêmica interessada do que da comunidade detentora do bem cultural. Esse quadro deveria, a partir de então, compor entre seus técnicos novas competências, como especialistas em antropologia, etnografia, musicologia, entre outros.

No entanto, apesar do exposto, esses programas não apresentam linhas de pesquisas voltadas especificamente para a temática do artesanato, reconhecido dentro como patrimônio imaterial. Numa abordagem mais pontual, o PPG em Patrimônio Cultural e Sociedade UNIVILLE apresentou cinco dissertações na temática, destacando em sua proposta de forma bastante clara sua preocupação com o desenvolvimento da sociedade e suas relações dicotômicas indivíduo-coletividade, cultura-natureza, civilização-barbárie, materialidade-imaterialidade, tradição-modernidade, poder-dominação, estado-sociedade, global-local, fé-razão, ciênciatecnologia, teoria-prática. Por sua vez, o PPG em Gestão do Patrimônio Cultural - PUC/GO, que foi um dos mestrados que mais apresentou produção acadêmica (três trabalhos), atualmente encontra-se desativado, o que dificultou o acesso às informações referentes à sua constituição.

No que se refere ao PPG em Memória Social e Patrimônio Cultural - UFPEL, mesmo fazendo parte da sua descrição a inserção da cidade de Pelotas nas 173 cidades contempladas com a ação governamental PAC cidades Históricas e relevantes pesquisas no campo do patrimônio imaterial ou intangível, sendo referência pela realização do Inventário Nacional de Referências Culturais - Doce Pelotense, uma parceria entre o IPHAN, o BID e a UNESCO, o programa 
apresentou apenas uma dissertação na área da temática elencada nessa pesquisa.

O PPG em Patrimônio Cultural - UFSM contabilizou 170 dissertações concluídas, conforme dados informados na Plataforma Sucupira, até setembro de 2018, no entanto apenas uma na temática abordada.

Em relação às produções acadêmicas, pode-se observar que a área de História está pautando as discussões, seja em relação aos autores das dissertações, como também pela área de conhecimento dos orientadores das pesquisas aqui mencionadas.

As dissertações elencadas mostram uma convergência quanto à desvalorização da produção artesanal em relação à competição mercadológica atual, sendo essa a motivação primeira das propostas de pesquisa.

Outro aspecto a ser pontuado acerca das concepções das pesquisas é que elas descrevem a atividade artesanal como condição de subsistência social e econômica do artesão, principalmente ligada às mulheres, mas também quanto condição da subsistência de identidades e tradições culturais, destacando uma concepção voltada muito mais aos processos e aos sujeitos desses bens culturais.

Apesar dos avanços desde as definições propostas na Constituição Federal de 1988, acerca do que seriam os patrimônios culturais brasileiros, contemplando os patrimônios materiais e imateriais e garantindo de fato a representatividade da diversidade cultural brasileira e de todos os programas que conferem uma mudança na concepção das políticas culturais, pouco se tem produzido academicamente naqueles programas que mais deveriam se destacar no que se refere ao produto da cultura popular - o artesanato.

Diante de todas as questões apresentadas, é certo que muito ainda pode ser dito e feito no campo do patrimônio. O mesmo serve para pensar o artesanato como uma categoria do patrimônio, assim como os saberes e fazeres, que oferece entendimento além do corpóreo do objeto ou do produto final, evidenciando a conexão entre o sujeito e o objeto.

Sabe-se que nos programas, aqui elencados, muitos esforços vêm sendo feitos no sentido de ampliar os espaços de pesquisa na área do patrimônio, vide a diversidade do campo do conhecimento do corpo docente. Ao mesmo tempo, sabe-se também das dificuldades materiais no sentido de fomento à execução das pesquisas, o que é um valor significativo a estas produções.

Não se pode ignorar o momento político desfavorável à continuidade dos investimentos às práticas ligadas à educação e à cultura, apontando para um imperativo de que essas áreas devam ser ampliadas e constituírem-se em espaços de resistência a esses modelos transnacionais que objetivam a invisibilidade das culturas locais.

\section{Referências}

ALVARES, F. C. Valorização dos aspectos formais dos artefatos confeccionados por guasqueiros do pampa gaúcho aplicados à joalheria. 2014. 169p. Dissertação (Mestrado em Patrimônio Cultural) - Universidade Federal de Santa Maria, Santa Maria, 2014. 
ARONI, B. Por uma etnologia dos artefatos: arte cosmológica, conceitos mitológicos. IN: Proa - Revista de Antropologia e Arte [on-line]. Ano 2, vol. 1, n. 2, set. 2010. Disponível em: <http://www.ifch.unicamp.br/proa/ArtigosII/brunoaroni.html>. Acesso em: 15 out. 2018.

BAUMAN, Z. Ensaios sobre o conceito de cultura. Tradução: Carlos Alberto Medeiros. Rio de Janeiro: Zahar, 2012.

Bergerot, V. Colcha de retalhos: os Bastidores do Patrimônio. 2006. 140p. Dissertação (Mestrado em Gestão do Patrimônio Cultural) - PUC-Goiás, Goiânia, 2006.

BEZERRA, H. G. Ensino de História: conteúdos e conceitos básicos. In: KARNAL, L. (Org.). História na sala de aula: conceitos, práticas e propostas. 6 ed. São Paulo: Contexto, 2010. p. 37-48.

BOURDIEU, P. A dominação masculina. Tradução: Maria Helena Kühner. 2. ed. Rio de Janeiro: Bertrand Brasil, 2002.

BRUNO, C. Museologia: algumas idéias para a sua organização disciplinar. Cadernos de Sociomuseologia, [S.1.], v. 9, n. 9, jun. 1996. p. 1-37. Disponível em: <https://revistas.ulusofona. pt/index.php/cadernosociomuseologia/article/view/291>. Acesso em: 20 out. 2019.

BRASIL. Constituição da República Federativa do Brasil: texto constitucional promulgado em 5 de outubro de 1988, com as alterações determinadas pelas Emendas Constitucionais de Revisão nos 1 a 6/94, pelas Emendas Constitucionais nos 1/92 a 91/2016 e pelo Decreto Legislativo no 186/2008. - Brasília: Senado Federal, Coordenação de Edições Técnicas, 2016. Disponível em: <https://www2.senado.leg.br/bdsf/bitstream/handle/id/518231/CF88_Livro_ EC91_2016.pdf>. Acesso em: 18 dez. 2016.

BRASIL. Portaria MIDC/SEMPE no 1.007-sei, de 11 de junho de 2018, no Diário Oficial da União. Brasília: $1^{\circ}$ ago. 2018, Edição 147, seção 1, p. 34. Disponível em: <http://www.in.gov.br/ materia/-/asset_publisher/Kujrw0TZC2Mb/content/id/34932949/do1-2018-08-01-portaria-n1-007-sei-de-11-de-junho-de-2018-34932930>. Acesso em: 14 out. 2019

BUENO, L. S. As técnicas tradicionais das fiandeiras e tecedeiras de Hidrolândia - Goiás. 2005. 114p. Dissertação (Mestrado em Gestão do Patrimônio Cultural) - PUC-Goiás, Goiânia, 2005.

CAVAlieri, M. M. Patchwork: retalhos de técnica, memória, arte e artesanato. 2011. 112p. Dissertação (Mestrado em Patrimônio Cultural e Sociedade) - Universidade da Região de Joinville, Joinville, 2011. 
CHAGAS, M. Casas e portas da memória e do patrimônio. In: Em Questão, Porto Alegre, v.13, n. 2, jul/dez. 2007. p. 207-224.

CORA, Maria Amelia Jundurian. Políticas públicas culturais no Brasil: dos patrimônios materiais aos imateriais. Rev. Adm. Pública, Rio de Janeiro, v. 48, n. 5, p. 1093-1112, oct. 2014. Disponível em: <https://doi.org/10.1590/0034-76121497>. Access em: 22 nov. 2019.

ESTEVES, V. K. No Caminho do Sabor e da Cultura: uma abordagem sobre a cozinha e o cotidiano da Estrada Bonita (Pirabeiraba Joinville/SC). 2010. 123p. Dissertação (Mestrado em Patrimônio Cultural e Sociedade) - Universidade da Região de Joinville, Joinville, 2010.

FERREIRA, N. S. de A. As pesquisas denominadas "estado da arte". Educação \& Sociedade, ano XXIII, n. 79, ago. 2002. p. 257-272.

FIGUEIRA, M. C. Colônia de Pescadores Z3, Pelotas - RS: da crise na pesca a expansão do turismo com base no patrimônio cultural. 2009. 157p. Dissertação (Mestrado em Memória Social e Patrimônio Cultural) - Universidade Federal de Pelotas, Pelotas, 2009.

FONSECA, M. C. L. Para além da pedra e cal: por uma concepção ampla de patrimônio cultural. IN: ABREU, R; CHAGAS, M. (Orgs.). Memória e Patrimônio: ensaios contemporâneos. 2. ed. Rio de Janeiro: Lamparina, 2009. p. 59-79.

FUNARI, P. P.; PELEGRINI, S. C. A. Patrimônio Histórico e Cultural. Rio de Janeiro: Zahar, 2006.

GONÇALVES, J. R. S. O Patrimônio como categoria do pensamento. IN: ABREU, R; CHAgAS, M. (Orgs.). Memória e Patrimônio: ensaios contemporâneos. 2. ed. Rio de Janeiro: Lamparina, 2009. p. 25-33.

KELLER, P. F. O artesão e a economia do artesanato na sociedade contemporânea. Política \& Trabalho. Revista de Ciências Sociais, n. 41, out, 2014, p. 323-347.

LARAIA, R. B. Cultura: um conceito antropológico. 23. ed. Rio de Janeiro: Zahar, 2009.

LATOUR, B. Jamais fomos modernos: ensaio de Antropologia Simétrica. Tradução de Carlos Irineu da Costa. Rio de Janeiro: Ed. 34, 1994.

LEGISLAÇÃO BRASILEIRA SOBRE PATRIMÔNIO CULTURAL [recurso eletrônico]. 2. ed. Brasília: Câmara dos Deputados, Edições Câmara, 2013. 349p. 
LIMA FILHO, M., ECKERT, C., BELTRÃO, J. (Orgs.). Antropologia e patrimônio cultural: diálogos e desafios contemporâneos. Blumenau, SC: Nova Letra, 2007. 367p.

MEIRA, E. D. A História de um Patrimônio Cultural: A Cachaça Morretiana. 2013. 137p. Dissertação (Mestrado em Patrimônio Cultural e Sociedade) - Universidade da Região de Joinville, Joinville, 2013.

MERENCIO, F. T. A imaterialidade do material, a agência dos objetos ou as coisas vivas: a inserção de elementos inanimados na teoria social. IN: Cadernos do LEPAARQ, v. 10, n. 20, jul/dez. 2013, p. 183-204.

MOURA, A. C. Patrimônio Imaterial. Disponível em: <http://artesanatosustentavel.com.br/2014/01/ patrimonio-imaterial/>. Acesso em: 29 abr. 2019.

NOGUEIRA, A. G. R. O campo do patrimônio cultural e a história: itinerários conceituais e práticas de preservação. Antíteses, v. 7, n. 14, p. 45-67, jul./dez. 2014.

NORA, P. Entre memória e História: a problemática dos lugares. São Paulo: Projeto História -PUC, 1993.

OLIVEIRA, L. L. Cultura é Patrimônio: um guia. Rio de Janeiro: Editora FGV, 2008.

PARRA, D. U. Os mercados campesinos de Bogotá: patrimônio cultural imaterial como instrumento de desenvolvimento. 2017. 178p. Dissertação (Mestrado em Patrimônio Cultural e Sociedade) - Universidade da Região de Joinville, Joinville, 2017.

PELEGRINI, S.C.A. O patrimônio cultural no discurso e na lei: trajetórias do debate sobre a preservação no Brasil. Patrimônio e Memória, UNESP - FCLAS - CEDAP, v. 2, n. 26, 2007, p. 54-77.

RADLEY, A. Artefactos, memória e sentido del passado. In: MIDDLETON, D.; EDWARDS, D. (Orgs.). Memória compartida: la natureza social del recuerdo y del olvido. Buenos Aires: Paidos, 1992. p. 63-76.

RIECHEL, Daiana. Memórias de agulhas: manifestação artesanal das bordadeiras de Jaraguá do Sul, Santa Catarina. 2014. 127p. Dissertação (Mestrado em Patrimônio Cultural e Sociedade) - Universidade da Região de Joinville, Joinville, 2014.

SANT'ANNA. M. A face imaterial do patrimônio cultural: os novos instrumentos de reconhecimento e valorização. IN: ABREU, R; CHAGAS, M. (Orgs.). Memória e Patrimônio:

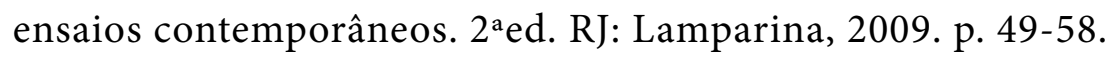

SANTOS, P. A. Olhos d' Água, Olhos d'Alma: de bem cultural a patrimônio goiano. 2005. 35p. Dissertação (Mestrado em Gestão do Patrimônio Cultural) - PUC-Goiás, Goiânia, 2005. 
SILVEIRA, F. L. A.; BEZERRA, M. Educação Patrimonial: perspectivas e dilemas. IN: LIMA FILHO, M., ECKERT, C., BELTRÃO, J. (Orgs.). Antropologia e patrimônio cultural: diálogos e desafios contemporâneos. Blumenau, SC: Nova Letra, 2007. p. 81-97.

SILVEIRA, F. L. A.; LIMA FILHO, M. F. Por uma antropologia do objeto documental: entre "a alma nas coisas" e a coisificação do objeto. Horizontes Antropológicos, Porto Alegre, ano 11, n. 23, p. 37-50, jan/jun. 2005.

VIEIRA, L. R. Registro e Salvaguarda do Patrimônio Cultural Imaterial no Brasil. Brasília: Núcleo de Estudos e Pesquisas/ CONLEG/Senado, setembro/2016 (Texto para Discussão no 211). Disponível em: <http://www.senado.leg.br/estudos>. Acesso em: 29 set. 2018.

UNESCO. Convenção para Salvaguarda do Patrimônio Cultural Imaterial. Paris: Unesco, 2003. Disponível em <http://portal.iphan.gov.br/uploads/ckfinder/arquivos/ConvencaoSalvaguarda.pdf>. Acesso em: 29 set. 2018.

VARINE. H. de. As raízes do futuro: O patrimônio a serviço do desenvolvimento local. Tradução de Maria de Lourdes Parreiras Horta. Porto Alegre: Medianiz, 2012. 